\title{
OS SENTIDOS DA ARTE ESTRANGEIRA NO BRASIL: EXPOSIÇÕES DE ARTE NO CONTEXTO DA SEGUNDA GUERRA MUNDIAL
}

\author{
Paulo Knauss \\ Departamento de História \\ Universidade Federal Fluminense
}

\begin{abstract}
Resumo
O trabalho tem como objeto as relações entre arte estrangeira e arte nacional no Brasil. O foco são as exposições de arte organizadas por diversos países no contexto político da Segunda Guerra Mundial. Nesse sentido, o ponto de partida é da caracterização da arte e das exposições como instrumento da diplomacia, promovendo tendências artísticas no Brasil. A concorrência política informa variantes das artes plásticas. Ao final, a análise destaca como a recepção da arte européia no Brasil conduziu a uma apropriação nacionalizadora das formas artísticas estrangeiras. Assim, a proposta consiste numa investigação sobre os sentidos da arte estrangeira no Brasil.
\end{abstract}

Palavras-chave: História da Arte; Arte no Brasil; Arte estrangeira

The foreign art in Brazil: expositions of art in the context of World War II

\begin{abstract}
The issue of this paper is the relationship between foreign art and national art in Brazil. The focus is on the art exhibitions organized by different countries in the political context of the Second World War. In this sense, the starting point is the characterization of art and exhibitions as a diplomacy instrument, promoting different art tendencies in Brazil. The political concurrence informed plastic arts variations. At the end, the analysis highlights how the reception of European art in Brazil has driven to a nationalizing appropriation of the foreign artistic forms. Thus, the proposal consists in a research about the senses of foreign art in Brazil.
\end{abstract}

Keywords: History of Art; Art in Brazil; Foreign Art 


\section{ARTE E DIPLOMACIA}

Os estudos sobre a história da arte no Brasil se caracterizam pela ênfase na discussão do caráter nacional da arte. Essa ênfase é ainda mais sublinhada na abordagem da arte moderna brasileira. Assim, a historiografia da arte tem valorizado o estudo de artistas e criações brasileiras que representam a identidade nacional. Ainda que se reconheça a importância de mestres estrangeiros na formação de artistas nacionais e a influência de formas plásticas internacionais na criação da arte brasileira, pouco se tem investigado a presença e circulação da arte estrangeira, especialmente da arte européia, no Brasil. A construção de coleções de arte que tinham como foco principal a arte européia serve como exemplo de como a arte estrangeira teve posição de destaque no gosto brasileiro do século XIX e no início do século XX. ${ }^{1}$

No sentido de caracterizar a presença da arte estrangeira no Brasil, é possível investigar práticas de promoção, circulação e crítica da imagem artística para identificar processos de apropriação que afirmar os sentidos da arte estrangeira no Brasil. Isso nos remete à história da construção de laços entre arte nacional e arte estrangeira e de suas influências mútuas. Entre as práticas de promoção da arte estrangeira no Brasil se destaca a produção de exposições de arte. A história das exposições no Brasil ainda não se constitui num tema muito abordado na historiografia, mas, sobretudo, percebe-se uma ausência de referências sobre a promoção de exposições de arte estrangeira. A história de sua promoção remete à história da construção do entrelaçamento de arte e diplomacia, por meio da promoção da arte de caráter nacional no estrangeiro organizada pelos serviços culturais da diplomacia oficial. Nesse exercício diplomático, desenrola-se também um trabalho de propaganda de modelos artísticos e de promoção de uma crítica de arte que conduz o pensamento e o olhar sobre a arte. O campo da história de exposições de arte, nesse caso, se relaciona com a história das relações internacionais. Trata-se, assim, de valorizar um território de fronteira que aproxima arte e política, a partir de uma história cultural das relações internacionais. $^{2}$

No campo dos laços entre arte e diplomacia no Brasil, cabe ressaltar que a participação das artes plásticas brasileiras nas grandes exposições nacionais e internacionais ainda não recebeu um estudo específico. Deixa-se, assim, de destacar a história do quadro de dom Pedro II que foi feito especialmente para a exposição da Filadélfia de 1876 e que chamou a atenção na ocasião, como quase tudo que envolveu a presença do único monarca que visitou os EUA até então. Há inúmeras outras peças que se destacam nesse universo, como a estátua de João Caetano que acompanhou o quadro do imperador em 1876 aos EUA, ou o modelo da estátua eqüestre do imperador brasileiro exposto ao ar livre junto ao 
pavilhão brasileiro da exposição de Paris de $1867 .{ }^{3}$ Pode-se destacar, igualmente, a organização do grande salão de artes plásticas realizado no edifício da antiga Escola Nacional de Belas Artes como parte dos eventos da exposição universal do centenário da Independência, no Rio de Janeiro, em 1922. De um lado, pode-se levantar a hipótese que essas iniciativas de promoção das artes em torno das exposições universais envolviam a criação artística no plano oficial e sob o controle do Estado e da instituição acadêmica das artes, tal como nos salões oficias. Mas antecipam em muito tempo as representações nacionais das bienais de São Paulo, por exemplo. É preciso atentar para o fato, portanto, de que a participação nas exposições universais se realizava como complemento e parte da ação diplomática.

Por sua vez, a história da arte moderna no Brasil pode ser igualmente investigada a partir de exposições estrangeiras realizadas na cidade do Rio de Janeiro. Em 1928, por exemplo, na Escola Nacional de Belas-Artes, sob a organização do galerista Heuberger, foi inaugurada exposição de arte moderna alemã. Essa exposição inovou ao apresentar as peças em uma única fila, e não amontoadas como era o hábito até então. No ano seguinte, foi a vez da montagem da exposição Deutscher Werkbund, preparada pela Associação de Artes Decorativas da Alemanha. Estas iniciativas foram produtos da iniciativa do galerista Heuberger, que se dedicou a aproximar Brasil e Alemanha a partir das artes. ${ }^{4}$ Mas é em 1930 que ocorre na cidade a primeira mostra de obras de arte da Escola de Paris. Foi no Palace Hotel que se apresentou cerca de 90 obras francesas na Grande Exposition d'art moderne, trazida pelo pintor brasileiro Vicente do Rego Monteiro e pelo crítico francês Géo-Charles, um dos editores da revista Montparnasse. O público do Rio de Janeiro viu pela primeira vez obras de Braque, Dufy, Léger, Picasso, Wlamink, Miró, entre outros, antes da afirmação mesmo da noção de Escola de Paris. ${ }^{5}$

\section{ARTE FRANCESA NAS AMÉRICAS}

Após a Primeira Guerra Mundial, no contexto da Liga das Nações e do trabalho de promoção da paz internacional, é que a diplomacia começa a se complexificar e constituir os serviços culturais diplomáticos. Na França, esse espaço foi ocupado a partir de 1920 com a organização do Service des Oeuvres Françaises à l'Etranger, subordinado à direção dos negócios políticos e comerciais do Ministério dos Negócios Estrangeiros. Sua missão envolvia a expansão intelectual da França no exterior. Esse serviço diplomático surgiu como desdobramento do Bureau des Écoles et des Oeuvres Français à l'Étranger, estabelecido em 1910 e recriado em 1918, no contexto da Primeira Guerra. O reforço veio, ainda, com a criação em 1915, em pleno conflito militar mundial, do Office 
des Relations Publique et de Propagande, e que ficou conhecido também como Maison de Presse, pela atividade editorial desenvolvida. Depois da Guerra, essa repartição se transformou no Commissariat Général de l'Information et de la Propagande. Nesse mesmo contexto da Primeira Grande Guerra, o Ministério da Instrução Pública da França criou, em 1916, o Service de Décentralisation Artistique à L'Étranger, transformado em $1918 \mathrm{em}$ Service d'Études d'Action Artistitique à l'Étranger, subordinado à direção de belas-artes, para promover a arte francesa no exterior. ${ }^{6} \mathrm{O}$ desenvolvimento de suas atividades em colaboração com o Ministério dos Negócios Estrangeiros terminou conduzindo ao estabelecimento, em 1922, da Association Française d'Éxpansion et d'Échanges Artistiques, como organismo executivo dos dois ministérios, e que foi transformada, em 1934, na Association Française d'Action Artistique, conhecida pela sigla AFAA e que existe ainda hoje. Essa associação assumiu a tarefa de divulgar a arte francesa no mundo e garantir o bom acolhimento dos artistas francesas em outros países.

O que importa, no entanto, é salientar que a propaganda de Estado no plano internacional foi estruturada no período entre-guerras para promover diversas iniciativas de intercâmbio cultural, entre elas a promoção de exposições de arte nacional no estrangeiro. Desse modo, exposições européias de arte foram dirigidas para as Américas, especialmente a partir dos anos da década de 1930. No Brasil, por exemplo, a cronologia das exposições de arte do Museu Nacional de Belas Artes indica a importância da ação dos serviços culturais da diplomacia estrangeira. Entre 1938 e 1949, o MNBA recebeu 54 exposições, sendo ao menos 16 delas associadas à colaboração estrangeira, ou seja, mais de $1 / 4$ ou quase 1/3 das exposições do museu. Itália, Canadá, Grã-Bretanha, Alemanha, Estados Unidos e França são os países que marcam presença no programa de exposições do MNBA nesse período.

Com a abertura do Museu Nacional de Belas-Artes, em 1938, ficou criado um espaço privilegiado no Brasil para esse tipo de colaboração artística a partir da diplomacia. Um ano antes, em 1937, o ministério das Relações Exteriores brasileiro havia criado o Serviço de Cooperação Intelectual. ${ }^{7}$ Mas o contexto de abertura do museu coincide com a afirmação do Estado Novo no Brasil e, sobretudo, com o contexto internacional das rivalidades políticas que vão levar à Segunda Guerra Mundial. Esse quadro político da cena internacional envolveu a utilização da arte como instrumento de propaganda de Estado. Esse ciclo se abre no Brasil em 1940 com a Exposição de Arte Francesa: de David a nossos dias e se completa em 1949 com a Exposição de Arte Contemporânea Francesa: de Manet a nossos dias. Ambas as exposições percorreram diversos países da América do Sul. A ação francesa nesse campo das exposições de arte se 
completa, ainda, com a produção, em 1945, de uma exposição chamada Pintores franceses dos nossos dias.

Todas essas exposições trouxeram ao Brasil grandes referências da arte francesa. A primeira apresentou obras de mestres da arte acadêmica como David, Gros, Ingres, ou Delacroix, pinturas da Escola de Barbizon de Courbet e Corot, por exemplo, e se completava com quadros impressionistas de Manet, Renoir e Monet, entre outros nomes do catálogo. A terceira exposição francesa apresentou ao público artistas emblemáticos como Braque, Dufy, Derain, Léger, Manet, Matisse, Monet, Picasso, Pisarro, Renoir, Sisley, entre outros, dando destaque aos diferentes gêneros dos impressionistas, os fauves e os cubistas. Essas produções foram comandadas pelo grupo de conservadores do Museu do Homem que estiveram envolvidos na criação do Museu Nacional de Arte Moderna da França, e que se tornaram autores fundamentais da interpretação da arte moderna na França por meio de sua produção de crítica de arte. Entre eles, destaca-se o nome de René Huyghe que fez conferências na América do Sul em 1939, antes do circuito da exposição De David a nossos dias e participou da produção dos catálogos das três exposições francesas do contexto histórico da Segunda Guerra. A cronologia permite entrelaçar estas exposições de arte francesa: a primeira produzida nos estertores do regime da Terceira República, antes da Guerra se iniciar; a segunda marca a presença da França na cena das artes depois da Guerra; e a terceira completa o período de negociação para restituir obras de arte confiscadas como botim de guerra, o que envolvia a operação de retorno das obras de arte à França. Esse foi o caso da exposição que chegou no Brasil em 1940 e que permaneceu nas Américas durante todo o período da Guerra ao ser alojada na National Gallery de Washington, nos EUA, tendo sido incorporada à coleção permanente. Algumas peças chegaram a ser colocadas em exibição como parte de coleção própria do museu. O mesmo aconteceu, na mesma época, com a exposição de artes decorativas que permaneceu no Museu Nacional de Artes Decorativas de Buenos Aires, na Argentina até sua restituição à França. Destaca-se, no entanto, que estas exposições francesas - especialmente a última - ofereceram a oportunidade no Brasil e na América do Sul de admirar obras de artistas impressionistas e da Escola de Paris.

\section{POLÍTICA DA ARTE}

A experiência da Guerra é marcante para crítica artística inscrita nas páginas dos catálogos das exposições de arte francesa enviadas à América do Sul, no contexto da Grande Guerra. Os textos do catálogo da exposição de arte francesa de 1949, De Manet a nossos dias, estabelecem alguns parâmetros para a avaliação crítica da história da arte na França. O texto de Gaston Diehl sublinha a 
continuidade da pintura francesa, caracterizando um percurso que se estende do Impressionismo do fim do século XIX para atravessar o período entre-guerras e a afirmação no contexto da Segunda Guerra Mundial. Nas palavras do autor francês: "A rude apresentação dos acontecimentos provocou uma acelerada maturidade dos espíritos. Encontramo-nos brutalmente envelhecidos de muitos anos. Uma cristalização brusca das idéias e das necessidades se opera [...]". ${ }^{8}$ René Huyghe, por sua vez, em outro texto do mesmo catálogo de 1949, procura apresentar que o mundo das artes francesas resistiu ao contexto do domínio nazista ao afirmar: "Precipita-se a crise latente e, a partir de 1941, a pintura francesa, em plena ocupação, responde ao invasor, reunindo todas as forças da sua audácia". ${ }^{9}$ A guerra se caracteriza, assim, como uma experiência marcante para o mundo da arte na França. Jacques Jaujard, na abertura do catálogo da exposição francesa de 1945, pontua a cronologia do movimento de exposições de arte francesa no Brasil: "No momento em que a guerra eclodiu na Europa, a França apresentava na América do Sul a exposição De David a nossos dias. Assim que a paz renasceu, nós nos apresentamos novamente no continente latino com uma exposição [Pintores franceses de hoje] que, seguindo a trilha natural da precedente, mostrará o ponto atual das nossas pesquisas estéticas." 10

Assim, o diretor geral de artes e letras francês situa a exposição de 1945 claramente em relação à exposição de 1940 e caracteriza as duas como complementares. Assim, não apenas a arte demarca o conteúdo da exposição, mas, igualmente, a política termina dando sentido à iniciativa de promoção artística. Entre a guerra e a paz é que a autoridade cultural francesa situa as duas exposições francesas em torno do período do início e do fim do conflito mundial. Esse período, no entanto, é apresentado por Jacques Jaujard como um intervalo, ao dizer: "Após as provas que atravessamos, é uma profunda satisfação podermos dirigir-nos prontamente a nossos amigos da América do Sul, retomar e desenvolver intercâmbio intelectual com eles e com a grande nação brasileira". ${ }^{11}$ A linearidade proposta entre as duas exposições se configura como forma de superar um período intervalar. O intervalo de tempo se apresenta como período de afirmação da força, enquanto o tempo da promoção das duas exposições de arte representa a aproximação da humanidade. Nas palavras de Jaujard: "Este envio [da exposição] responde a uma outra necessidade. A agressão germânica fez, mais uma vez, ascender no mundo o peso da força, a ameaça de submissão do pensamento à força. Hoje podem renascer as atividades desinteressadas que fazem a nobreza da humanidade, aquelas que o homem se propõe a trabalhar pelo homem." 12

Claramente, o que se observa nesta passagem é a vontade de identificar a iniciativa francesa da exposição com a promoção da solidariedade por contraste com a agressão germânica. Opera-se um jogo de identidades nacionais no plano 
internacional. A transposição disto para o campo das relações entre o Brasil e a França é assumida no final do texto ao fazer referências à influência por meio da presença artística de Debret, Taunay, Grandjean de Montigny como mestres franceses do ensino das artes no Brasil. A exposição de 1945 atualiza, assim, iniciativas de outros tempos ao retomar os rumos da linearidade da história, como se ela tivesse sido interrompida pela guerra. Deixa de lado, o fato de que os artistas mencionados eram napoleônicos e que deixaram a França, no início do século XIX, pela derrota e perseguição de seu grupo político, não se podendo atribuir a eles necessariamente a tarefa de traduzir a aproximação diplomática da França do Brasil, considerando o contexto político de sua época. Por fim, o texto de Jacques Jaujard procura, também, afirmar o caráter da França de modo positivo diante dessa conjuntura histórica particular: "Nós queremos mostrar que, mesmo nos momentos mais difíceis, jamais desesperamos, que conservamos sempre intacta nossa fé na civilização. A obra construída por nossos artistas nesse tempo tão sombrio é acima de tudo esta afirmação". ${ }^{13}$

Sem dúvida, a arte é eleita, então, como um recurso para afirmar a posição da França diante da história e das outras nações do mundo naquele tempo do pós-guerra. No mesmo catálogo de 1945, René Huyghe corrobora as palavras Jacques Jaujard, anotando logo no início de seu texto: "Durante cinco anos de opressão, a França viveu voltada para si mesma, esperando com fervor a libertação, e preparando-a. Esse momento foi preparado por meio das armas clandestinas da Resistência, e, também, pelo espírito. O pensamento e as artes permaneceram vivos, e com uma paixão ainda mais ardente, como garantia da continuidade intacta do país e de sua independência profunda”.

No discurso de René Huyghe, o mundo francês das artes no contexto da Guerra se identificava com o movimento de resistência à opressão. Essa identificação entre arte e política se afirmou na sua própria trajetória pessoal de crítico de arte que se tornou capitão da Resistência. Esse percurso, no entanto, foi marcado pela carreira de conservador de pinturas do museu do Louvre, onde ingressou em 1927 e foi efetivado em 1930, aos 26 anos, antes de ser nomeado conservador-em-chefe em 1937. ${ }^{14}$ Contudo, esse cruzamento biográfico entre a crítica de arte e a política não foi exclusividade de René Huyghe. O mais célebre personagem desse cruzamento foi Jean Cassou, que iniciou sua carreira no serviço público, no fim dos anos de 1930, durante o governo do Front Populaire, quando Jean Zay ocupou o cargo de ministro da Instrução Pública e das Belas-Artes na França. Nessa altura, Cassou participou de reformas importantes no campo das artes e acompanhou a organização da Exposição Internacional de Paris, em 1937, que deu origem à criação do Museu Nacional de Belas Artes que ele dirigiu depois da reinauguração do museu em 1947, permanecendo no posto de diretor 
do museu até 1966. Mas, ainda no início de sua carreira, tornou-se adjunto de Louis Hautecoeur, conservador do Museu de Luxemburgo e ex-professor de toda a geração de conservadores que incluía René Huyghe e Jean Cassou. Depois de ser preso e afastado de seu posto no governo de Vichy, Jean Cassou entrou para o movimento da Resistência, o que fez com que depois da Libertação fosse consagrado como herói nacional, assim como René Huyghe. ${ }^{15}$ Ambos representam uma geração de críticos de arte franceses marcados pela experiência da resistência e que são caracterizados pela ruptura com o regime autoritário de Vichy. As duas biografias, no entanto, se cruzam com a história de Louis Hautecoeur, conservador do Museu do Louvre de destaque no seu tempo, e que assumiu a direção da Secretaria-Geral de Belas Artes durante o regime de Vichy, entre 1940 e 1944. ${ }^{16}$ Depois da guerra, René Huyghe e Jean Cassou contribuíram com seu depoimento para a absolvição de Hautecouer diante do tribunal de guerra. Mesmo que nunca tenha conseguido se desligar inteiramente desta passagem de sua vida, Hautecoeur continuou como um crítico de arte ativo e valorizado na França do pós-Guerra. A menção a estas trajetórias aponta para o dilema da política das artes na França durante o período da Guerra. De um lado, há uma memória da resistência que se identifica com o afastamento de várias personalidades em relação ao regime do marechal Pétain. Essa memória é corroborada ainda pela repressão ou restrição às atividades de vários artistas conhecidos na França daquele tempo. ${ }^{17}$ Por outro lado, há uma evidente permanência de alguns nomes em vários postos da administração pública no campo das artes, que sugere uma espécie de acomodação ao novo regime. A memória e os fatos da resistência eclipsam os espaços efetivos de colaboração.

Outro personagem desse período é Philippe Erlanger, que permaneceu de 1938 a 1968 na direção da Association Française d'Action Artistique - AFAA, atravessando, assim, na mesma posição diferentes fases da política francesa, inclusive o período do autoritarismo. No seu caso, a condição de judeu e o parentesco com a família de banqueiros Camondo, que encontrou seu fim no quadro do holocausto, não o impediu de se adaptar ao regime de Vichy e guardar sua posição no aparelho de Estado, como dirigente da AFAA. ${ }^{18}$ Há, assim, uma ordem de fatores que indica que Vichy não interrompeu a administração das artes na França e impõe à crítica histórica desse contexto limites hagiográficos da história institucional, para repetir o argumento de Denis Rolland. ${ }^{19}$

\section{RIVALIDADES}

Na cronologia das exposições do MNBA, observa-se que no contexto do início da Guerra, ainda em 1941, organizam-se exposições de pintura italiana e gravura alemã no museu brasileiro. Depois da declaração de guerra que marcou 
o ingresso do Brasil no conflito militar mundial, as iniciativas desses países do Eixo desapareceram do museu em favor de outras participações, como Inglaterra, Canadá e Estados Unidos. No fim do ano de 1941, chegou ao Rio de Janeiro a grande exposição de Pintura Contemporânea Norte-Americana, que integrou uma iniciativa que percorreu vários países da América Latina, promovida pelo conhecido Bureau Interamericano liderado por Nelson Rockefeller, e que foi base da construção da política de boa vizinhança dos EUA. ${ }^{20} \mathrm{O}$ catálogo dessa exposição abre com uma imagem figurativa de cunho surrealista de John Atherton, The Back Yard e contém obras de influência cubista, como o quadro My Egypt, de Charles Demuth, ou o exemplo da pintura de Max Weber, Chinese Restaurant, conhecido quadro de 1915. Entre os 12 artistas que integraram a mostra havia obras de Edward Hopper, entre elas a pintura Early Sunday Morning (1930), além de pinturas de Geórgia O’Keefe, como The White flower (1931), apresentando provavelmente pela primeira vez a criação de artistas norte-americanos que vão se destacar no pós-Guerra e no quadro de afirmação da pintura de vanguarda dos EUA. ${ }^{21}$

$\mathrm{Na}$ abertura do catálogo brasileiro, a exposição norte-americana é caracterizada pelo comitê de arte responsável pela curadoria, como mais que um "testemunho de amizade entre as Américas", pois pretendia apresentar "um retrato da vida e do pensamento contemporâneo nos Estados Unidos". O texto deixa claro o vínculo entre a exposição e a diplomacia ao afirmar que "a arte é indiscutivelmente o melhor dos embaixadores". ${ }^{22}$ No texto de introdução de Helen Appleton Read aparece, ainda, a afirmação de que "o nosso conhecimento de qualquer civilização está na proporção direta do conhecimento que possuímos de sua Arte", deixando clara a idéia de que a exposição procurava representar a civilização norte-americana. ${ }^{23}$ Nesse sentido, a iniciativa da exposição se definia como ação de propaganda de Estado. Contudo, é no texto crítico de Read que aparece a seguinte afirmação: "O que é espantoso em vista dessa influência, é o fato da nossa Arte [dos EUA] ter desenvolvido uma manifestação tão independente, e, ainda mais, terem os nossos artistas de hoje ficado tão ligados à América". ${ }^{24}$

Mesmo reconhecendo uma certa genealogia européia que estava situada entre a tradição do realismo e do modernismo, a arte nos EUA era afirmada na exposição de 1941 como um modelo de criação particular e alternativo às fontes da Europa. Em 1943 foram produzidas, ainda, no Museu Nacional de Belas Artes / MNBA, no Rio de Janeiro, três exposições norte-americanas. Depois da Guerra, a influência dos EUA nas artes do Brasil se identifica pela criação dos Museus de Arte Moderna, de gestão privada, segundo o modelo do MOMA de Nova York.

De todo modo, também aí se apresenta a intenção de afirmar a arte nos EUA com fontes diferentes da arte da Escola de Paris européia. Há a menção 
em afirmar os EUA como referência para a arte daqueles tempos, por oposição aos modelos europeus. Isso vai fica mais claro, no segundo pós-Guerra, com a promoção da action painting e a obra de artistas como Jackson Pollock, tal como demonstrou Serge Guilbaut num livro de referência para essa discussão. ${ }^{25}$ O contexto histórico, portanto, apresentou uma situação de disputa de modelos da arte, que vai ganhar expressão no pós-Guerra, mas tem sua origem marcada pela Segunda Guerra Mundial. É possível sugerir que a arte se constituiu nesse contexto político numa arena das rivalidades diplomáticas, que colocou a noção de arte em debate. A crítica de arte, assim, acompanhou e colaborou com a diplomacia.

\section{APROPRIAÇÃO BRASILEIRA}

O conhecimento das fontes da arte no mundo por meio das exposições estrangeiras despertou uma interrogação sobre as relações do Brasil com a arte estrangeira. Em 1949, depois da exposição francesa De Manet a nossos dias passar pelo Rio de Janeiro, o Ministério da Educação e Saúde, por meio do Serviço de Documentação, publicou um livro de autoria de Antonio Bento, chamado Manet no Brasil, que incluía as cartas do pintor francês escritas durante sua viagem ao Brasil. O subtítulo da obra revelava que se tratava de um estudo comemorativo da passagem do centenário da visita do artista francês ao Rio de Janeiro, quando ainda servia na Marinha. A promoção da exposição que tinha na obra de Manet a referência para a pintura contemporânea francesa ganhava um sentido suplementar no Brasil, pelo fato que o conhecido pintor francês e precursor da pintura impressionista produziu seus primeiros desenhos como marinheiro em viagem ao Brasil. Logo no início da introdução do livro, a idéia de que a viagem de Manet ao Brasil fazia parte da história da pintura moderna devido servia para assinalar a sua influência sobre o movimento de renovação das artes plásticas. No livro, anota-se também que a experiência individual de Manet antecedeu, ainda, outras viagens marcantes no século XIX para a história da pintura européia, como a viagem de Henri Rousseau ao México e de Gauguin pelas Antilhas e o Panamá, antes de ir para a ilha de Taiti. Segundo Antonio Bento, a experiência dessas viagens teria contagiado o retorno ao primitivismo e o repúdio ao classicismo que marcaram a obra desses artistas viajantes. O autor concluía: "O contacto com a natureza do Brasil dera, por outro lado, ao jovem Manet uma visão pura, instintiva e virginal das coisas". ${ }^{26}$ Nesse sentido, tratava-se de "um convívio no espaço, com a natureza americana", que acompanhou o desejo de Manet e dos artistas modernos de, segundo as palavras do autor, "refazer o mundo e de proceder uma completa revisão de valores, mudando as concepções estéticas". ${ }^{27}$ Assim, Antonio Bento demarca a importância do Brasil para a reno- 
vação da arte moderna da Europa - "o contacto de Manet com o mundo plástico deste país [o Brasil] iria também concorrer para regeneração da pintura européia contemporânea". ${ }^{28}$

Nessa introdução, Antonio Bento caracteriza a história do início da pintura de Manet, que deu origem ao movimento artístico do Impressionismo, do seguinte modo: "Tendo gravado em sua retina suprasensível a intensidade da luz brasileira, Manet foi sobretudo o primeiro pintor contemporâneo a suprimir sombras escuras, as gradações delicadas, os matizes sutis e a recorrer diretamente às grandes chapadas de cores simples e puras. E partindo das observações feitas no Rio, desde logo verificou que as sombra, na arte acadêmica, era apenas o trompe l'oeil do sol. Passou conseqüentemente a simplificá-la, tornando-a ao mesmo tempo mais luminosa, para desespero dos colegas de ofício, dos críticos e do público de sua geração. [...[ Nunca de fato a pintura havia submetido o mundo exterior a uma análise visual tão completa e obstinada. A Escola do plein-air teve em Manet o seu chefe, sendo levada depois pelos impressionistas às últimas conseqüências. [...] A lição foi decisiva para jovem artista, que fez desse princípio [a luz] o fundamento de sua pintura." ${ }^{29}$ Desse modo, fazendo uso de expressões em francês, o autor procurou afirmar que foi no Rio de Janeiro que o artista francês Manet teve a sua primeira aula prática de pintura. E assim, a problemática da luz no impressionismo tem o Brasil como referência. A interrogação da arte francesa se desloca para localizar a origem da arte moderna européia no Brasil, ao mesmo tempo, que relaciona o desenvolvimento da arte moderna com o Brasil. Pode-se dizer, portanto, que, no discurso de Antonio Bento, patrocinado pelo Ministério da Educação brasileiro, a inovação moderna do impressionismo é apresentada por uma filiação brasileira.

De modo conclusivo, há aí a apresentação de uma versão alternativa da origem da arte moderna que tem o Brasil como berço e referência. Essa interpretação original, no entanto, se explica no contexto de afirmação da integração dos povos, mas anuncia, igualmente, a intenção de afirmação do Brasil como pólo de referência no concerto das nações a partir da história da arte. A crítica de arte se encarrega, assim, de promover uma leitura brasileira da história da arte. O que se observa é um processo de apropriação da arte estrangeira, que se afirma como produto nacional. Desse modo, a leitura proposta da história do Impressionismo como movimento moderno da arte traduz a construção de uma imagem universal do Brasil integrado na modernidade a partir da arte. Há diante da arte estrangeira o exercício de um olhar nacional.

Recebido em 14 de junho de 2008 


\section{NOTAS}

${ }^{1}$ Cf., KN AUSS, Paulo. 0 cavalete a paleta: arte e prática de colecionar no Brasil. Anais do Museu Histórico N acional, Rio de Janeiro, v.33, p.23-44, 2001.

${ }^{2} \mathrm{Cf}$., RO LLAN D, D enis (coord.). H isto ire culturelle des rélations internationales : carrefour méthodologiques. Paris, L'H armattan, 2004.

${ }^{3}$ Cf., KN AUSS, Paulo. 0 desafio de representar o futuro: a estátua eqüestre de d. Pedro II e os sentidos da escultura monumental no Brasil. Anais do Museu H istórico N acional, Rio de Janeiro, v. 37, p. 235-252, 2005.

${ }^{4}$ CF., LIM A, Lucia de Meira. 0 Palace Hotel: um espaço de vanguarda no Rio de Janeiro. IN : CAVALCAN TI, Lauro (org.). Q uando o Brasil era moderno: artes plásticas no Rio de Janeiro, 1905-1960. Rio de Janeiro, Aeroplano, 2001. p. 60-119.

${ }^{5} \mathrm{Cf}$., Idem.

${ }^{6}$ Cf. RO LLAN D, D enis. Entre mepris et desinteret: les oeilleres de la propagande d'État française en direction de l'Amérique latine (1914-1940). IN : RO LLAN D, D enis et alii (dir.). Les Républiques en propagande. Paris, L'H armattan, 2006. p. 269-278.

${ }^{7}$ Agradeço essa informação à gentileza de Raquel Paz dos Santos.

${ }^{8}$ Cf., De Manet a nossos dias; exposição.... Rio de Janeiro, Ministério da Educação e Saúde, outubro, 1949.

${ }^{9} \mathrm{Cf}$., Idem.

${ }^{10} \mathrm{Cf}$. Peintres français d'aujourd' hui - art décoratifs - Rio de Janeiro, 1945. [tradução nossa]

${ }^{11} \mathrm{Cf}$., Idem.

${ }^{12} \mathrm{Cf}$., Idem.

${ }^{13} \mathrm{Cf}$., Idem.

${ }^{14}$ Cf., HUYGHE, René. Une vie pour I'art : de Léonard à Picasso. Paris, Ed. de Fallo is, 1994.

${ }^{15} \mathrm{Cf}$., CASSO U, Jean. Une vie pour la liberté. Paris, Robert Laffont, 1981.

${ }^{16} \mathrm{Cf} .$, PO U LAIN , Caroline. La permanence des Beaux-Arts dans la fracture de Vichy: I'action e Louis Hautecouer au sécretariat génèral des Beaux-Arts, 1940-1944. Écoles des C hartes, 2001.

${ }^{17} \mathrm{Cf}$., CO N E, M ichèle C. Artist under Vichy: a case of prejudice and persecution. Princeton, N J, Princeton University Press, 1992. Um panorama das questões da arte na França sob o regime de Vichy se encontra em: BERTRAN D D O RLÉAC, Laurence. Histoire de I'art -, Paris - 1940-1944: ordre national, traditons et modernités. Paris, Publications de la So rbonne, 1986.

${ }^{18} \mathrm{Cf}$., ERLAN G ER, Philippe. La France sans étoile ; so uvenirs d'avant-guerre e du temps de I'O ccupation. Paris, Plon, 1974.

${ }^{19} \mathrm{Cf}$. RO LLAN D, D enis. Les limites hagio graphiques de I' histoire institutionelle : les Affaires étragères, I' action culturelle de la France à l' étranger et le syndrome de Vichy. Le Temp des Savoirs ; revue interdisciplinaire de L'Institut U niversitaires de France. Paris, n. 3, p.155-177. 2001.

${ }^{20}$ U ma consideração dessa exposição aparece no trabalho: GIUN TA, Andréa. Misión imposible: $\mathrm{N}$ elson Rockefeller y la cruzada del internacionalismo artístico. IN : SALVATO RE, Ricardo (comp.). Culturas imperiales: experiencia y representación en América, Asia y Africa. Buenos Aires, Beatriz Viterbo, 2005. p. 185-211.

${ }^{21}$ Cf., Pintura contemporânea norteamericana; catálogo. Rio de Janeiro, 1941.

${ }^{22} \mathrm{Cf}$., Idem. p. 5.

${ }^{23} \mathrm{Cf}$., Idem. p. 9

${ }^{24} \mathrm{Cf}$., Idem.

${ }^{25} \mathrm{Cf}$., GU ILBAUT, Serge. Comment $N$ ew York volal'idée d'art moderne: expressionisme abstrait, liberté et guerre fro ide. Paris, $\mathrm{H}$ achette, 2006.

${ }^{26}$ Cf., BEN TO , Antônio. Manet no Brasil. Rio de Janeiro, Ministério da Educação e Saúde, 1949. p. 9.

${ }^{27} \mathrm{Cf}$., Idem. p. 8 .

${ }^{28} \mathrm{Cf}$., Idem.

${ }^{29} \mathrm{Cf}$., Idem. p. 9. 